\title{
Flora da Usina São José, Igarassu, Pernambuco: Convolvulaceae
}

\author{
Flora of the Usina São José, Igarassu, Pernambuco: Convolvulaceae
}

\author{
Maria Teresa Buril ${ }^{1,2} \&$ Marccus Alves ${ }^{1}$
}

\begin{abstract}
Resumo
Convolvulaceae é uma família predominantemente tropical e compreende entre 1600 e 1700 espécies. O Brasil é um importante centro de endemismo do grupo, mas sua diversidade ainda é pouco conhecida e subestimada no país. A flora de Convolvulaceae da Usina São José, aqui apresentada, portanto, incrementa o conhecimento sobre a diversidade da família no Nordeste. Foram registradas doze espécies e cinco gêneros de Convolvulaceae na região: Bonamia maripoides, Evolvulus nummularius, Ipomoea bahiensis, I. hederifolia, I. nil, I. philomega, I. quamoclit, I. tiliacea, Jacquemontia glaucescens, J. sphaerostigma, Merremia macrocalyx e M. umbellata. O tratamento conta com chave de identificação, descrições, ilustrações e comentários para os táxons.
\end{abstract}

Palavras-chave: florística, liana, Mata Atlântica, taxonomia, trepadeira.

\begin{abstract}
Convolvulaceae is a predominantly tropical family and comprises between 1600 and 1700 species. Brazil is an important center of endemism of the group, but its diversity is still poorly understood and underestimated in the country. Therefore, the flora of Convolvulaceae from the Usina São José, presented here, increases the knowledge about the diversity of the family in the Northeast Brazil. Twelve species and five genera of Convolvulaceae is reported in the region: Bonamia maripoides, Evolvulus nummularius, Ipomoea bahiensis, I. hederifolia, I. nil, I. philomega, I. quamoclit, I. tiliacea, Jacquemontia glaucescens, J. sphaerostigma, Merremia macrocalyx, and M. umbellata. The treatment includes identification key, descriptions, illustrations, and comments for the taxa.
\end{abstract}

Key words: Atlantic rainforest, floristics, liana, taxonomy, vine.

\section{Introdução}

Convolvulaceae compreende entre 1600 e 1700 espécies agrupadas em 55 a 60 gêneros, e possui distribuição cosmopolita, com centro de diversidade na região tropical (Mabberley 1987; Austin 1998a). No Brasil, são reconhecidos 18 gêneros, sendo os mais representativos Ipomoea L., Evolvulus L. e Jacquemontia Choisy, aos quais pertence a maioria das cerca de 300 espécies registradas para o país. Ocorrem em formações vegetacionais variadas, desde a Caatinga até a Amazônia, sendo mais frequentes em ambiente de campos abertos e em bordas de mata (SimãoBianchini \& Pirani 1997; Souza \& Lorenzi 2005).

São geralmente trepadeiras sem gavinhas, ervas ou subarbustos, raramente arbustos ou holoparasitas áfilas (Cuscuta L.), quase sempre latescentes. As folhas são alternas, na maioria simples, por vezes lobadas a compostas, sem estípulas. As flores são dialissépalas, gamopétalas, campanuladas, infundibiliformes ou hipocrateriformes, com áreas mesopétalas proeminentes, estames epipétalos, ovário súpero e fruto do tipo cápsula valvar ou indeiscente (Simão-Bianchini \& Pirani 1997; Smith et al. 2004).

Grande parte das pesquisas aplicadas conduzidas com a família é focada na utilização e nas propriedades químicas e genéticas da Ipomoea batatas (L.) Lam., popularmente conhecida como batata-doce (Padda \& Picha 2008). No entanto, estudos recentes vêm demonstrando o potencial de outras espécies, principalmente para a indústria farmacêutica (Cervenka et al. 2008; Yen et al. 2008).

Segundo Gentry (1991), 26 famílias de angiospermas incluem $85 \%$ de todas as trepadeiras do Novo Mundo e Convolvulaceae agrega o 
segundo maior número de espécies. No Brasil, as discussões sobre a importância ambiental e ecológica da família ainda são pouco enfatizadas, apesar dela ser bem representada em nossa flora (Simão-Bianchini \& Pirani 2005; Simão-Bianchini 2009). Em vários inventários florísticos (e.g., Udulutsch et al. 2004; Tibiriçá et al. 2006; AlvesAraújo et al. 2008; Durigon et al. 2009), a família aparece entre aquelas com o maior número de espécies, sendo destacada principalmente na diversidade de trepadeiras. Na Região Nordeste, o conhecimento sobre a diversidade de Convolvulaceae é ainda mais restrito, principalmente devido à incipiência de especialistas na Região. A Flora de Convolvulaceae da Usina São José, em Igarassu, Pernambuco, apresentada $a$ seguir, vem, portanto, contribuir para o conhecimento da diversidade da família na Mata Atlântica ao Norte do rio São Francisco.

\section{Material e Métodos}

A Usina São José localiza-se na Zona da Mata Norte, a $28 \mathrm{~km}$ de Recife, no município de Igarassu, Pernambuco $\left(7^{\circ} 40^{\prime} 21,25^{\prime}\right.$ " $77^{\circ} 55,50,92$ "S e $34^{\circ} 54^{\prime} 14,25^{\prime \prime}-35^{\circ} 05^{\prime} 21,08^{\prime \prime} \mathrm{W}$ ) (Trindade et al. 2008). Compreende uma área total de $280 \mathrm{~km}^{2} \mathrm{e}$ possui aproximadamente 100 fragmentos florestais; seis deles foram selecionados para este estudo.

As coletas foram realizadas entre 2007 e 2010, em fragmentos que variam de 30 a 400 ha. Foram ainda agregadas informações obtidas a partir das coleções depositadas nos herbários ASE, HST, HUEFS, HURCA, HVASF, IPA, JPB, K, M, MAC, P, PEUFR, UFRN, UFP (siglas de acordo com Thiers
2009). As amostras botânicas foram processadas de acordo com as técnicas usuais em taxonomia vegetal (Mori et al. 1985) e os "vouchers" depositados no Herbário UFP, com duplicatas distribuídas para o IPA e RB.

As identificações foram realizadas com auxílio de bibliografia específica (O’Donell 1941; Robertson 1971; Austin 1975; Austin \& Cavalcante 1982; Gentry 1996; Austin 1998b; Simão-Bianchini 1998; Buril 2009) e comparação com amostras previamente identificadas por especialistas, incluindo os tipos. A caracterização morfológica seguiu principalmente Harris \& Harris (2000) e Stearn (2004), além de Gonçalves \& Lorenzi (2007) para a venação e forma da corola. O presente trabalho adota a organização apresentada para as demais famílias monografadas para a Usina São José (e.g., Alves-Araújo \& Alves 2010).

\section{Resultados e Discussão}

Doze espécies e cinco gêneros de Convolvulaceae foram registrados na Usina São José, sendo Ipomoea (6 espécies) o mais representativo em número de espécies, adicionando quatro à lista florística da área (Alves-Araújo et al . 2008). As espécies são, de modo geral, amplamente distribuídas na Mata Atlântica do Nordeste, e em alguns casos, a exemplo de I. bahiensis Willd. ex Roem. \& Schult., são comumente encontradas em capoeiras, áreas de borda, e com influência antrópica, desde a Caatinga (Buril 2009) até a Mata Atlântica. Em contraposição, Bonamia maripoides Hallier f. ocorre apenas no interior da mata, sendo incomum em áreas perturbadas.

\section{Tratamento Taxonômico}

\section{Chave de Identificação para as Convolvulaceae da Usina São José}

1. Lianas, látex abundante, ramos rugosos, às vezes com lenticelas verrucosas.

2. Folhas elípticas, largamente elípticas a ovadas, base cuneada ou arredondada, face abaxial densamente serícea, venação camptódroma ............................................................... 1. Bonamia maripoides

2'. Folhas ovadas, base cordada, puberulentas em ambas as faces, venação actinódroma .

6. Ipomoea philomega

1'. Ervas trepadeiras, eretas ou prostradas, subarbustos eretos ou escandentes, látex geralmente escasso, ramos lisos, sem lenticelas verrucosas.

3. Ervas prostradas, folhas inteiras, orbiculares, inflorescências unifloras axilares, gineceu com 2 estiletes 2. Evolvulus nummularius

3'. Trepadeiras herbáceas ou subarbustos eretos a escandentes, folhas compostas ou simples, inteiras ou lobadas, ovadas quando inteiras, inflorescências multifloras, raramente unifloras, gineceu com 1 estilete. 
4. Folhas simples inteiras.

5. Plantas pilosas, tricomas estrelados, frutos 8-valvares, sementes com anel de tricomas rijos na margem Jacquemontia

6. Tricomas glandulares principalmente nos ramos jovens, sépalas lanceoladas, flores com estilete inserto 10. J. sphaerostigma

6. Tricomas glandulares ausentes, sépalas orbiculares a obcordadas, flores com estilete exserto 9. J. glaucescens

5'. Plantas glabras a glabrescentes, tricomas simples, frutos 4-valvares, sementes glabras ou pilosas.

7. Tricomas na face abaxial da lâmina foliar restritos às nervuras secundárias, inflorescência em umbela, corola amarela, anteras retorcidas após a antese 12. Merremia umbellata

7'. Tricomas na face abaxial da lâmina foliar ausentes ou quando presentes nunca restritos às nervuras secundárias, inflorescência em dicásio, corola rósea ou roxa, anteras retas após a antese .

Ipomoea

8. Folhas com 7 pares de nervuras secundárias, 1 sépala externa menor (ca. $6 \times 4 \mathrm{~mm}$ ) que as demais $(8 \times 5 \mathrm{~mm})$, nunca rostradas 8. I. tiliacea

8'. Folhas com 6 pares de nervuras secundárias, sépalas externas e internas do mesmo tamanho (ca. $7 \times 4 \mathrm{~mm}$ ), as externas rostradas 3. I. bahiensis

4'. Folhas lobadas, pinatipartidas a palmadas.

9. Corola vermelha, hipocrateriforme, estames e estilete exsertos Ipomoea

10. Folhas pinatipartidas, sépalas lisas 7. I. quamoclit

10'. Folhas 3-5-lobadas, nunca aparentando uma folha pinada, sépalas com um rostro subapical 4. I. hederifolia

9'. Corola branca, azul ou rósea, infundibuliforme, estames e estilete insertos.

11. Folhas palmadas, inflorescência dicasial, anteras retorcidas após a antese 11. Merremia macrocalyx

11'. Folhas 3-lobadas, inflorescência uniflora axilar, anteras eretas após a antese

5. Ipomoea nil

Bonamia Thouars, Hist. vég. îsles France: 33. 1804. Lianas, raramente trepadeiras ou subarbustos. Folhas ovadas, elípticas, lanceoladas, oblongas ou lineares, glabras ou seríceas a vilosas na face abaxial. Inflorescências axilares, cimeiras, compostas ou simples, raramente flores isoladas, axilares. Flores pediceladas ou sésseis, corola azul, purpúrea ou rósea, raramente vermelha ou amarela, geralmente pubescentes na nervura mesopétala. Estames com tricomas glandulares na base dos filetes, anteras eretas. Ovário piloso a glabro, 2-carpelar, 2-locular, 2 estiletes, livres a parcialmente livres, estigmas globosos a capitados, reniforme ou raramente peltado. Fruto cápsula, 4-8valvar. Sementes largamente elípticas a trigonais, lisas ou punctadas, glabras ou ciliadas.

\section{Bonamia maripoides Hallier f., Bot. Jahrb. Syst.} 16:529. 1893.

Fig. 1 a-d

Liana, látex branco, abundante. Ramos maduros rugosos, seríceos, lenticelas verrucosas. Folhas 7,1$10,9 \times 3,7-5,6 \mathrm{~cm}$, cartáceas, inteiras, elípticas, largamente elípticas a ovadas, base cuneada ou arredondada, ápice agudo a acuminado, face abaxial densamente serícea, dourada, tricomas simples, raramente bífidos e assimétricos, face adaxial glabra, acinzentada; venação camptódroma, 7 pares de nervuras secundárias. Pecíolo 0,5-1,3 cm compr., seríceo. Dicásios 3-7-floros; pedúnculos ca. $1 \mathrm{~cm}$ compr., seríceos. Cápsula ca. 1,2 cm compr., globosa, 4-valvar, sépalas persistentes. Sementes trigonais ou largamente elípticas, lisas, glabras.

Material examinado: Mata da Cruzinha, 26.XI.2009, fr., J.D. García 1339 (UFP); Mata de Piedade, 18.IX.2009, J.D. García 1216 (UFP); Mata de Vespas, 12.III.2009, J.D. García 976 (UFP).

Material adicional: BRASIL. PERNAMBUCO: Paulista, estrada de Aldeia-Caetés, 14.V.1985, A. Chisppeta 556 (IPA). BAHIA: Uruçuca, 11.IX.1991, fr., A.M. Carvalho 3511 (HUEFS).

Espécie sul-americana, conhecida para a Amazônia e para a Mata Atlântica. No Nordeste, há apenas registros em Pernambuco e na Bahia. Na Usina São José, é encontrada no interior dos fragmentos ou em áreas mais úmidas, próximas a riachos. Às vezes confundida com representantes de Icacinaceae 
(Gentry 1996), dos quais difere pelos frutos, que nesta última são drupas. Devido à forma e coloração dos tricomas das folhas, pode ser confundida com espécies de Maripa, gênero frequente na Amazônia (Ribeiro et al. 1999), mas que apresenta tricomas glandulares na face abaxial das folhas e frutos indeiscentes. As sementes são trigonais quando formadas quatro por fruto e largamente elípticas em frutos com menos de quatro sementes.

Evolvulus L., Sp. pl. (ed. 2): 391. 1762.

Ervas ou pequenos arbustos, eretos ou prostrados. Folhas inteiras, lineares a orbiculares. Inflorescências axilares, pedunculadas ou sésseis, dicasiais, às vezes reduzidas a uma flor. Flores com pedicelos tão longos quanto o cálice, ou pedicelo aparentemente ausente, sépalas geralmente iguais entre si, corola infundibuliforme, hipocrateriforme ou rotácea, geralmente azul ou branca. Estames geralmente exsertos, anteras eretas. Ovário glabro, 2-carpelar, 2-locular, 2 óvulos por lóculo, 2 estiletes, livres ou parcialmente unidos, cada estigma profundamente bífido, lobos estigmáticos filiformes. Fruto cápsula, 4-valvar. Sementes lisas ou discretamente verrucosas.

2. Evolvulus nummularius (L.) L., Sp. pl. (ed. 2): 391.1762.

Fig. $1 \mathrm{e}$

Erva prostrada, sem látex. Ramos puberulentos, tricomas simples e longos, raízes nos nós. Folhas 4-8×3-7 mm, membranáceas, inteiras, orbiculares, base arredondada ou discretamente cordada, ápice arredondado, glabras; venação camptódroma, 3 pares de nervuras secundárias. Pecíolo ca. 1,5 $\mathrm{mm}$ compr., puberulento. Inflorescências unifloras, axilares, pedicelo ca. $2 \mathrm{~mm}$ compr., puberulento, 1 par de bractéolas ca. 1,2 mm compr., lineares. Sépalas iguais, ca. $3 \times 1 \mathrm{~mm}$, oblanceoladas, ciliadas. Corola ca. $5 \mathrm{~mm}$ compr., rotácea, distintamente lobada, glabra, branca. Estames de mesma altura. Disco nectarífero ausente. Ovário 2-locular, 2 óvulos por lóculo. Cápsula ca. 3 mm compr., ovoide, pedicelo reflexo.

Material examinado: Mata de Piedade, 16.XII.2009, fl., D. Cavalcanti 25 (UFP).

Material adicional: BRASIL. PERNAMBUCO: São Lourenço da Mata, Tapacurá, 11.V.2004, fl. e fr., M.S. Sobrinho 576 (UFP).

Amplamente distribuída no Novo e no Velho Mundo, ocorrendo em áreas de clareiras e ambientes antropizados (Austin \& Cavalcante 1982; Austin 1998b). Na Usina São José, ocorre ocasionalmente em áreas de borda com solo areno-argiloso.
Ipomoea L. Sp. pl.: 159. 1753.

Trepadeiras ou subarbustos, raramente arbustos ou árvores. Folhas inteiras a compostas, glabras ou pubescentes. Inflorescência axilar na maioria, 1-muitas flores em dicásios. Flores em pedicelos longos ou curtos, sépalas geralmente não acrescentes, corola infundibuliforme, campanulada ou hipocrateriforme, frequentemente rósea ou lilás, raramente amarela ou branca, nervura mesopetalina bem definida por duas veias distintas. Estames insertos ou raramente exsertos, triangulares na base, comumente de tamanhos diferentes, anteras eretas. Ovário às vezes pubescente, 2(3)-locular, 4(-6)-ovulado, estilete 1, estigmas 2(3)-globosos. Fruto cápsula, 4-valvar. Sementes geralmente 4 , glabras ou pubescentes.

3. Ipomoea bahiensis Willd. ex Roem. \& Schult., Syst. veg. 4: 789. 1819.

Fig. $1 \mathrm{f}-\mathrm{h}$

Trepadeira herbácea, látex branco, escasso. Ramos glabrescentes. Folhas 6,8-12,3×3,2-6,4 cm, membranáceas, inteiras, ovadas, base profundamente cordada a sagitada, ápice acuminado, glabrescentes; venação actinódroma, 6 pares de nervuras secundárias. Pecíolo $2-4,2 \mathrm{~cm}$ compr., às vezes com concentração de tricomas na axila. Dicásios 6-7floros, às vezes com a flor principal truncada; pedúnculo 4,2-6 cm compr., geralmente não ultrapassando a folha subtendente, 1 par de bractéolas persistentes, 2-4 mm compr., lineares. Sépalas 2 externas ca. $7 \times 4 \mathrm{~mm}$, largamente elípticas, base truncada, ciliadas, 3 internas ca. $7 \times 4 \mathrm{~mm}$, largamente elípticas, com rostro subapical. Corola 2,5-5 cm compr., infundibuliforme, glabra, roxa. Estames heterogêneos, 2 maiores, 3 menores, com tricomas na base; estilete inserto, maior que os estames; disco nectarífero ausente; ovário globoso. Cápsulas ca. $1 \mathrm{~cm}$ compr., largamente elípticas, 4valvares. Sementes densamente pilosas.

Material examinado: Mata de Macacos, 10.XII.2007, fl. e fr., P.Y. Ojima 110 (IPA, UFP); Mata de Pezinho, 25.II.2008, fr., P.Y. Ojima 115 (IPA, UFP); Mata de Piedade, 20.IX.2009, fl., J.D. García 1159 (UFP); 14.IX.2009, fl. e fr., J.D. García 1088 (UFP).

Endêmica do Brasil, bastante frequente, principalmente em áreas de capoeira, campos abertos e bordas de mata (Austin \& Huáman 1996), incluindo áreas de Caatinga (Buril 2009) a matas úmidas (Simão-Bianchini 2009). Na Usina São José, apresenta grande variabilidade na forma, de cordadas a sagitadas, e no tamanho foliar. Facilmente reconhecida pelas sépalas rostradas. 


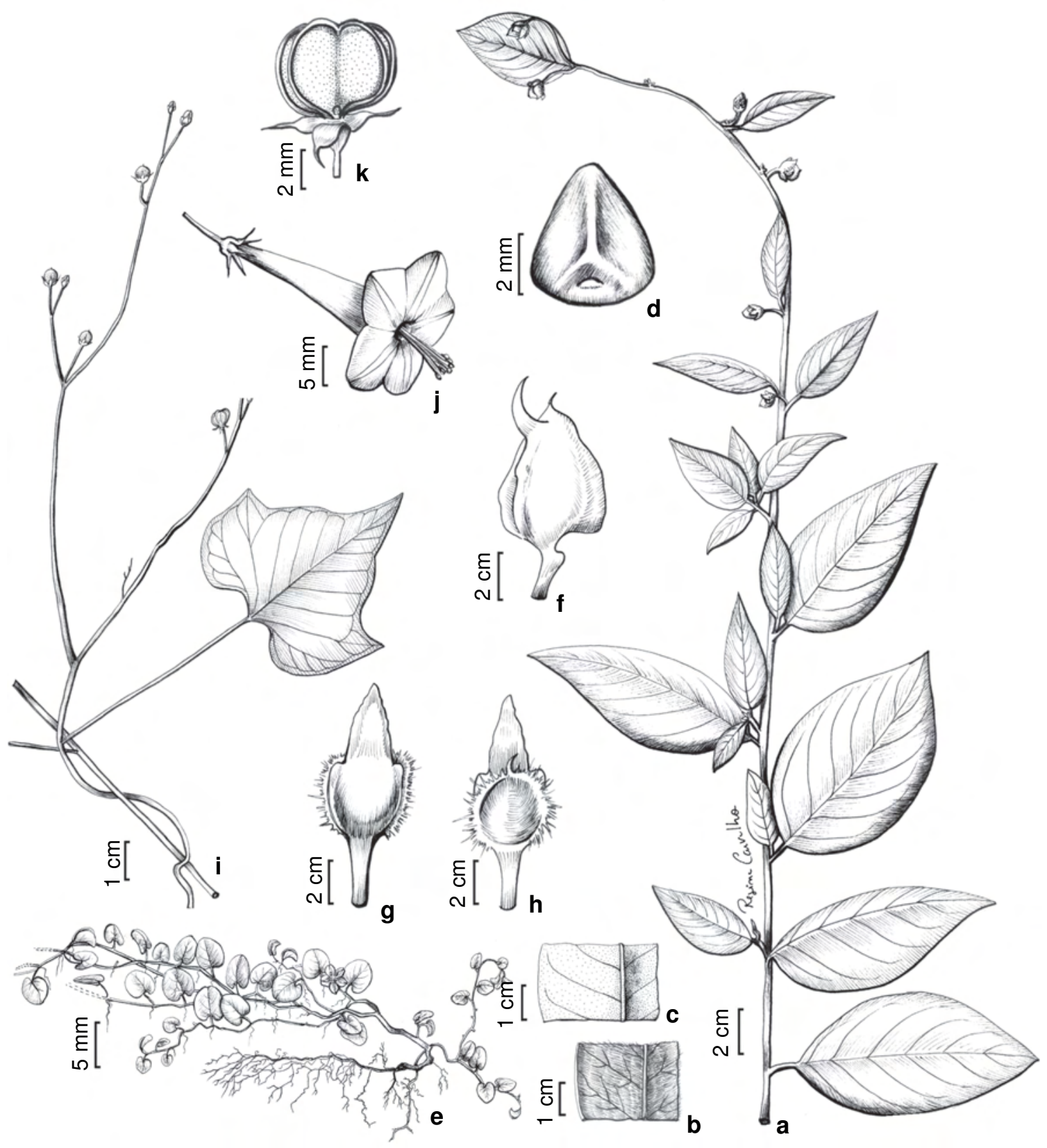

Figura 1 - a-d. Bonamia maripoides (García 1339) - a. ramo florífero; b. detalhe da face abaxial da folha; c. detalhe da face adaxial da folha; d. semente, vista frontal. e. Evolvulus nummularius (Cavalcanti 25) - hábito. f-h. Ipomoea bahiensis (García 1159) - f. sépala externa; g. sépala interna, vista dorsal; h. sépala interna, vista frontal. i-k. I. hederifolia (Melo et al. 141) - i. ramo florífero; j. flor, vista lateral; k. fruto com septos persistentes, vista lateral. Figure 1 - a-d. Bonamia maripoides (García 1339) - a. fertile branch; b. detail of the lower surface of leaf; c. detail of the upper surface leaf; d. seed, frontal view; e. Evolvulus nummularius (Cavalcanti 25) - habit. f-h. Ipomoea bahiensis (García 1159) - f. external sepal; g. internal sepal, dorsal view; h. internal sepal, frontal view. i-k. I. hederifolia (Melo et al. 141) - i. fertile branch; j. flower, lateral view; k. fruit with persistent septs, lateral view. 
4. Ipomoea hederifolia L., Syst. nat. (ed. 10): 925. 1759.

Fig. 1i-k

Trepadeira herbácea, látex branco. Ramos glabros a glabrescentes. Folhas 5,2-14,5 × 3,9$10,5 \mathrm{~cm}$, membranáceas, 3-5-lobadas, base profundamente cordada, ápice agudo a acuminado; venação actinódroma, 7 pares de nervuras secundárias. Pecíolo até 7,5 cm compr., glabro, raramente com tricomas na região do nó. Cimeiras dicasiais, com paracládios laterais monocasiais, escorpioides ou dicasiais; pedúnculo 5,3-12,4 cm compr., glabro, bractéolas lineares. Sépalas iguais, ca. $6 \times 3 \mathrm{~mm}$, oblongas, com um rostro subapical de ca. $3 \mathrm{~mm}$ compr. Corola 3,5-4 cm compr., hipocrateriforme, vermelha, glabra. Estames exsertos, iguais; estilete exserto, pouco maior que os estames; disco nectarífero ausente; ovário cônico. Cápsula ca. $6 \mathrm{~mm}$ compr., globosa. Sementes densamente pubérulas.

Material examinado: Mata de Piedade, 13.IX.2007, fl. e fr., A. Melo et al. 141 (IPA e UFP), 18.IX.2009, fl. e fr., J.D. García 1212 (UFP).

Amplamente distribuída nas Américas tropical e subtropical, ocorrendo desde o México até o sul da Argentina, comum em áreas de capoeira e bordas de mata (Austin \& Huáman 1996). No Brasil, é considerada daninha, principalmente em regiões da Mata Atlântica (Simão-Bianchini 1998), sendo raramente citada para o semi-árido. Na Usina São José, assim como Ipomoea quamoclit, diferencia-se das demais espécies do gênero pela corola hipocrateriforme vermelha, mas são facilmente distintas entre si pelas folhas pinatipartidas em I. quamoclit.

\section{Ipomoea nil (L.) Roth., Catal. bot.: 36. 1797.}

Fig. 2 a

Trepadeira herbácea, látex branco. Ramos hirsutos. Folhas 6,2-11×7-9,5 cm, membranáceas, 3-lobadas, ovadas, base profundamente cordada, ápice acuminado a caudado, face abaxial glabrescente a adaxial puberulenta, com tricomas restritos principalmente às nervuras principais; venação actinódroma, 6 pares de nervuras secundárias. Pecíolo 1-3 cm compr., glabrescente. Inflorescências unifloras, axilares; pedúnculo 5-6,5 cm compr., hirsuto, com 1 par de bractéolas lineares, ca. $5 \mathrm{~mm}$ compr. Sépalas iguais, $0,8-1 \mathrm{~cm}$ compr., lineares, com tricomas hirsutos na base, ca. $2,5 \mathrm{~mm}$ compr., dourados. Corola ca. $4 \mathrm{~cm}$ compr., infundibuliforme, glabra, branca. Estames heterogêneos, 2 maiores, 3 menores, insertos, tricomas na base, anteras eretas após a antese; estilete inserto, maior que os estames, lobos estigmáticos oblongos; disco nectarífero ausente; ovário globoso. Cápsula ca. $1 \mathrm{~cm}$ compr., globosa. Material examinado: Mata de Piedade, 28.X.2009, fl. e fr., J.D. García 1251 (UFP).

Material adicional: BRASIL. PERNAMBUCO: Mirandiba, Serra do Tigre, 30.V.2006, fl. e fr., K. Pinheiro 114 (UFP).

Amplamente distribuída nas Américas (Austin \& Huáman 1996), ocorre em capoeiras, campos abertos e bordas de mata (SimãoBianchini 1998). De uma forma geral, as flores desta espécie são bem marcantes pela coloração azul-celeste com a fauce do tubo alva. Contudo, esse pode ser um caráter plástico na espécie, variando do branco ao róseo. Também é considerada uma espécie invasora e daninha (Simão-Bianchini 1998).

6. Ipomoea philomega (Vell.) House, Ann. New York Acad. Sci. 18(6): 246. $1908 . \quad$ Fig. 2 b-d

Liana, látex branco, abundante, lenticelas planas. Ramos rugosos, quando jovens glabrescentes. Folhas 9,5-27 × 7,5-26 cm, cartáceas, inteiras, ovadas, base cordada, ápice acuminado a cirroso, quando jovens lanulosas, as mais desenvolvidas puberulentas em ambas as faces; venação actinódroma, 8 pares de nervuras secundárias, 3 divergindo da base. Pecíolo 1,2-4,8 cm compr., puberulento. Tirsos 9-18-floros; pedúnculo $12-16 \mathrm{~cm}$ compr., bractéolas caducas. Sépalas 2 externas 1,8-2 $\times 1,5-1,6 \mathrm{~cm}$, ovadas, base levemente cordada, ápice agudo, 3 internas 1-1,2× $1-1,1 \mathrm{~cm}$, orbiculares, ápice arredondado, mucronulado, côncavas. Estames subiguais, dilatados na base, puberulentos; estilete inserto, maior que os estames; disco nectarífero ausente; ovário globoso. Cápsula ca. $2 \mathrm{~cm}$ compr., globosa. Sementes pilosas. Material examinado: Mata de Piedade, 24.V.2008, fl., A. Melo et al. 358 (IPA, UFP); 7.III.2009, J.D. García et al. 935 (UFP); 15.IX.2009, fl. e fr., J.D. García 1100 (UFP).

Há registros da espécie desde o México até a América do Sul tropical, no Brasil, Equador, Colômbia, Guianas e Venezuela (Austin \& Huáman 1996). Na Usina São José, apesar de também ocorrer em áreas de borda, é frequente no interior da mata, alcançando o dossel, podendo desenvolver caule bastante robusto e lignificado. O látex branco é abundante, as folhas mais velhas podem alcançar $30 \mathrm{~cm}$ compr. e, nas folhas jovens, a face abaxial apresenta coloração púrpura. 


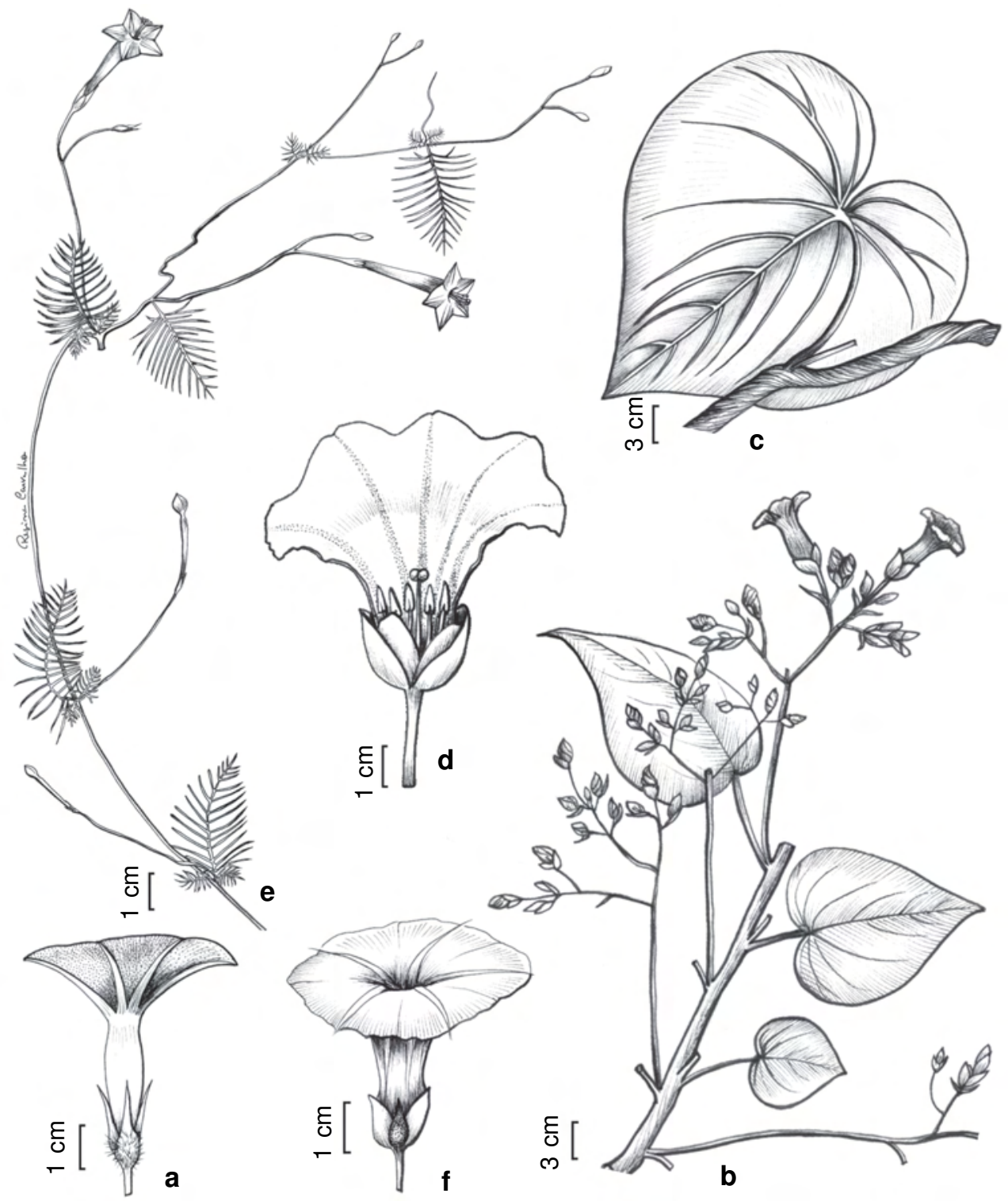

Figura 2 - a. Ipomoea nil (García 1251) - flor, vista lateral. b-d. I. philomega (García 1100) - b. ramo florífero; c. detalhe da folha; d. flor sem parte da corola. e. I. quamoclit (Alves-Araújo 531) - ramo florífero. f. Ipomoea tiliacea (Nascimento 655) - flor, vista lateral.

Figure 2 - a. Ipomoea nil (García 1251) - flower, lateral view. b-d. I. philomega (García 1100) - b. fertile branch; c. detail of leaf; d. flower without part of corola. e. I. quamoclit (Alves-Araújo 531) - fertile branch. f. Ipomoea tiliacea (Nascimento $655)$ - flower, lateral view.

7. Ipomoea quamoclit L., Sp. pl. 1: 159. 1753.

Fig. $2 \mathrm{e}$

Trepadeira herbácea, látex escasso e transparente. Ramos delgados, glabros. Folhas $2,2-4,5 \times 2-4,2 \mathrm{~cm}$, membranáceas, pinatipartidas, lobos lineares, agudos, gemas $0,5-2 \mathrm{~cm}$ compr., semelhantes às folhas, profundamente lobadas, glabras. Pecíolo 0,3-2 cm, glabro. Cimeiras monocasiais, geralmente 2-floras; pedúnculo 4 $6 \mathrm{~cm}$ compr. Sépalas iguais, ca. 1,2 $\times 0,6 \mathrm{~cm}$, largamente elípticas, base arredondada, ápice mucronado. Corola até $4 \mathrm{~cm}$ compr., hipocrateriforme, glabra, vermelha. Estames e estilete exsertos; disco nectarífero presente; ovário globoso. Cápsula ca. $6 \mathrm{~mm}$ compr., elíptica. Sementes com tricomas em blocos. 
Material selecionado: Mata dos Macacos, 16.VIII.2007, fl. e fr., A. Alves-Araújo et al. 531 (IPA, UFP).

Distribuída do México a Argentina, com exceção de algumas ilhas da América Central (Austin \& Huáman 1996). É amplamente cultivada como ornamental, e algumas vezes citada como ruderal. As flores, vermelhas e hipocrateriformes, são semelhantes às de Ipomoea hederifolia, porém suas folhas pinatipartidas a distinguem facilmente daquela espécie.

8. Ipomoea tiliacea (Willd.) Choisy, Prodr. 9: 375. 1845.

Fig. $2 \mathrm{f}$

Trepadeira herbácea, látex branco. Ramos glabros a glabrescentes. Folhas 3,5-13,3 × 2,8$11,2 \mathrm{~cm}$, membranáceas, inteiras, ovadas, base cordada, ápice acuminado, glabras; venação actinódroma, 7 pares de nervuras secundárias, com 4 destas convergindo da base. Pecíolo 4,3-7,8 cm compr., glabro. Dicásios laxos, 3-7-floros; pedúnculo 7,5-11 cm compr., glabro, bractéolas ca. 2 mm compr., subuladas, caducas. Sépalas 1 externa maior ca. $6 \times 4 \mathrm{~mm}$, oblanceolada, 1 externa e 3 internas ca. $8 \times 5 \mathrm{~mm}$, obovadas, ápice cuspidado a acuminado, glabras, paleáceas no fruto. Corola ca. $5 \mathrm{~cm}$ compr., infundibuliforme, glabra, rósea. Estames de tamanhos diferentes, 2 maiores e 3 menores, insertos, com tricomas na base; estilete inserto, maior que os estames; disco nectarífero ausente; ovário globoso. Cápsula ca. $8 \mathrm{~mm}$ compr., globosa. Sementes densamente pilosas.

Material selecionado: Engenho Campinas, 14.XI.2007, fl. e fr., L.M. Nascimento \& G. Batista 655 (IPA, PEUFR, UFP).

Registrada para o Brasil, Colômbia, Suriname, Guiana Francesa, Venezuela, México e países da América Central (Austin \& Huáman 1996). No Brasil, é referida principalmente para a Mata Atlântica (Simão-Bianchini 1998). Na Usina São José, pode ser diferenciada das demais espécies de Ipomoea pela presença de uma sépala externa menor que as internas, com consistência paleácea.

Jacquemontia Choisy, Mém. Soc. Phys. Genève 6: 476. 1833.

Trepadeiras herbáceas ou lianas, ervas ou subarbustos. Folhas inteiras, geralmente cordadas, glabrescente ou densamente pubérulas, tricomas estrelados, 3-7-ramificados. Inflorescência do tipo cimeira com 3-muitas flores, brácteas ausentes ou presentes em grande quantidade. Flores sésseis ou pedunculadas, infundibuliformes, azuis ou brancas, raramente com outra cor. Estames de tamanhos diferentes, puberulentos na base, anteras eretas. Ovário glabro, 2-carpelar, 2-locular, 4-ovulado, estilete 2-lobado, lobos largamente elípticos, planos, a raramente filiformes. Fruto cápsula, 8-valvar. Sementes trigonais, com anel de tricomas rijos na margem.

\section{Jacquemontia glaucescens Choisy, Mém. Soc.} Phys. Genève 8(1): 64. $1837 . \quad$ Fig. $3 \mathrm{a}-\mathrm{i}$

Trepadeira herbácea, látex branco. Ramos com indumento velutino, tricomas 5-(7)-armados. Folhas 5-7,3×2,3-4,7 cm, membranáceas, inteiras, ovadas, base arredondada, ápice agudo a obtuso, raramente mucronado, face abaxial densamente velutina, coloração glauca, tricomas 5-7-armados, face adaxial pubescente, quando secas com coloração marrom, tricomas 5-(7)-armados; venação camptódroma, 7 pares de nervuras secundárias. Pecíolo 0,6-2,3 cm compr., velutino. Cimeiras dicasiais umbeliformes, com até 12 flores; pedúnculo de tamanho variável, em ramos jovens as inflorescências podem parecer sésseis ou com pedúnculo bem curto, ca. $5 \mathrm{~mm}$ compr., em ramos desenvolvidos alcançam ca. $4 \mathrm{~cm}$ compr., bractéolas ausentes. Sépalas 3 externas ca. $4 \times 3 \mathrm{~mm}$, coriáceas, orbiculares, côncavas, puberulentas, 2 internas 5$6 \times 4-5 \mathrm{~mm}$, obcordadas, ciliadas. Corola 1,9$2,3 \mathrm{~cm}$ compr., infundibuliforme, glabra, azul. Estames maiores 2, menores 3, com tricomas na base; estilete exserto, lobos estigmáticos cilíndricos, mais longos que largos; disco nectarífero presente, ovário globoso. Cápsula ca. $6 \mathrm{~mm}$ compr., ovoide, 8 -valvar. Sementes trigonais, lisas.

Material examinado: Mata de Piedade, 20.IX.2009, J.D. García 1161 (UFP); 15.IX.2009, fl. e fr., J.D. García 1104 (UFP); 15.IX.2009, fr., J.D. García 1099 (UFP); 15.IX.2009, fl., J.D. García 1095 (UFP); 28.VII.2007, fl., A. Melo et al. 95 (IPA, UFP); Mata de Vespas, 12.III.2009, fr., J.D. García 977 (UFP); Mata de Zambana, 13.III.2009, fr., J.D. García et al. 990 (UFP).

Endêmica do Brasil, predominantemente em áreas de Mata Atlântica e nos brejos de altitude do Nordeste. Na Usina São José, é a espécie de Convolvulaceae mais comum, formando densas populações nas bordas dos fragmentos. Devido à base espessa dos caules é aqui tratada como uma liana de caule fibroso persistente. Pertence a um complexo de espécies bastante semelhantes morfologicamente e pode ser relacionada a $J$. holosericea (Weinm.) O'Donell, diferenciando-se principalmente pelas folhas discolores, pela proporção do tamanho entre as sépalas externas e as internas e pelo indumento dos ramos (O’Donell 1953). 


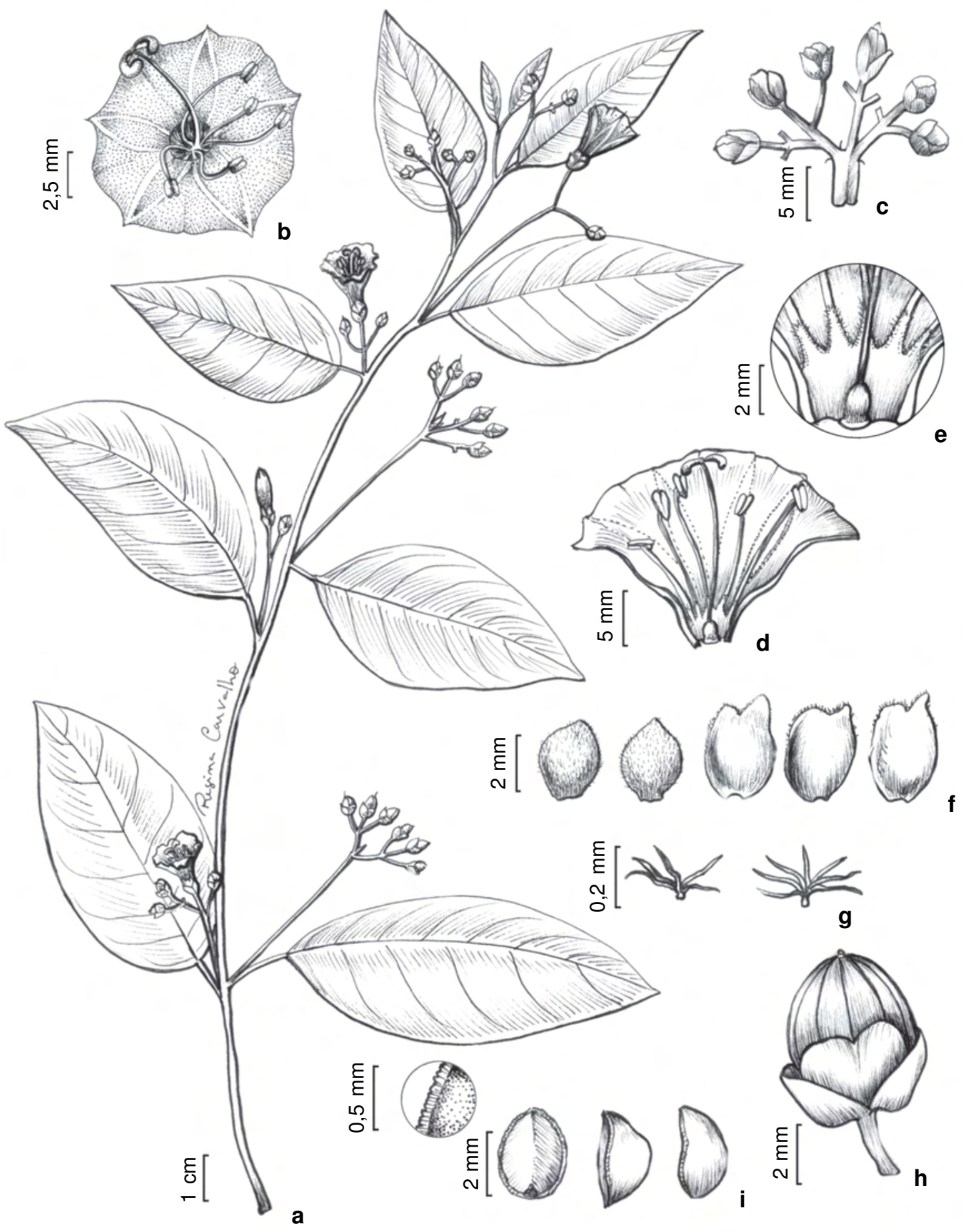

Figura 3 - a-i. Jacquemontia glaucescens (García 1104) - a. ramo florífero; b flor, vista frontal. c. inflorescência; d. corte longitudinal da flor; e. detalhe do ovário e a base dos filetes; f. sépalas externas (2) à esquerda, as internas (3) à direita; g. tricomas; h. fruto; i. semente, da esquerda para direta, detalhe dos tricomas na margem, face ventral e vistas laterais.

Figure 3 -a-i. Jacquemontia glaucescens (García 1104) - a. fertile branch; b. flower in a frontal view; c. inflorescence; d. longitudinal cut flower; detail of the ovary and the base of filaments; f. external sepals (2) at left and internal sepals (3) at right; g. trichomes; h. fruit; i. seed, from left to right, margin with detail of trichomes, ventral face, lateral views. 
10. Jacquemontia sphaerostigma (Cav.) Rusby, Bull. Torrey Bot. Club 6: 151. $1899 . \quad$ Fig. 4 a-g

Trepadeira herbácea, látex branco, escasso. Ramos pilosos, tricomas simples ou 3-armados homogêneos ou heterogêneos com um dos braços 3 vezes mais longo do que os demais. Folhas 2,4-4,3 $\times$ 1,4-2,4 cm, membranáceas, inteiras a sinuosas, lanceoladas a ovadas, base cordada, ápice agudo a acuminado, puberulentas, tricomas 3-armados com 1 dos braços bem mais longo; venação camptódroma, 6 pares de nervuras secundárias. Pecíolo $0,7-1,5 \mathrm{~cm}$ compr., glabrescente. Cimeira monocasial umbeliforme, 4-9-flora; pedúnculo 3,6-9,8 cm, com tricomas 3armados e glandulares, brácteas ca. $4 \mathrm{~mm}$ compr., lanceoladas, quando secas com coloração vinácea. Sépalas iguais, ca. $7 \mathrm{~mm}$ compr., lanceoladas, com tricomas 3-armados homogêneos e heterogêneos, e tricomas glandulares, não acrescentes no fruto. Corola infundibuliforme, ca. $1 \mathrm{~cm}$ compr., glabra, azul. Estames 3 maiores e 2 menores, com tricomas curtos na base; estilete inserto, lobos estigmáticos largamente elípticos, planos; disco nectarífero ausente; ovário oblongo. Cápsula 3-4 mm compr., globosa. Sementes trigonais, lisas.

Material selecionado: Mata de Piedade, 17.IX.2009, fl. e fr., J.D. García 1117 (UFP).

Ocorre desde o sul dos Estados Unidos até o Brasil (Austin \& Cavalvante 1982; Austin 1998b). No Brasil, ocorre tanto em áreas fragmentadas de Mata Atlântica quanto na Caatinga. Na Usina São José, está presente em ambientes de capoeiras, sendo mais rara que $J$. glaucescens. Pode ser confundida com J. agrestis (Mart. ex Choisy) Meisn. e J. evolvuloides Meisn., devido à presença de tricomas glandulares principalmente em ramos mais jovens das duas espécies. Contudo, a estrutura das inflorescências é bastante peculiar, geralmente cimeiras congestas com 3-7 flores, enquanto nas outras espécies elas são cimeiras laxas similares a racemos, geralmente 3-floras.

Merremia Dennst., Schlüssel Hortus malab.: 34. 1818.

Trepadeiras geralmente herbáceas e sem látex. Folhas inteiras, lobadas ou digitadas com 3-7 folíolos. Inflorescências axilares, unifloras ou com poucas flores, politélicas. Flores pediceladas, brancas, raramente amarelas ou róseas. Estames geralmente glabros na base, anteras retorcidas na antese. Ovário glabro, 2- ou 3-carpelar, 2- ou 3locular, 4-6-ovulado, estilete 1, estigma 2-globoso. Fruto cápsula, 4-valvar. Sementes trigonais.
11. Merremia macrocalyx (Ruiz \& Pav.) O’Donell. Lilloa 6: 506. 1941.

Fig. $4 \mathrm{~h}$

Trepadeira herbácea, látex não observado. Ramos glabros, às vezes com tricomas restritos às regiões nodais. Folhas 4-5,2 $\times 6,2-8,3 \mathrm{~cm}$, cartáceas, palmadas, folíolos com margem inteira ou discretamente serreada, oblanceolados, base cuneada, ápice agudo, glabros. Pecíolo 1-2,3 cm compr., glabro. Cimeira dicasial laxa, 3-7-flora, às vezes com a flor principal truncada; pedúnculo $6,4-8,5 \mathrm{~cm}$ compr., brácteas e bractéolas ausentes. Sépalas subiguais, $1,7-2 \times 0,7-0,8 \mathrm{~cm}$, elípticas a ovadas, acrescentes no fruto, paleáceas, coloração dourada. Corola 3,4-3,8 cm compr., infundibuliforme, glabra, alva. Estames 4 menores e 1 maior, insertos, com tricomas na base; disco nectarífero presente; ovário globoso, 4-locular, 1 óvulo por lóculo. Cápsula ca. 1 cm compr., globosa.

Material examinado: Mata de piedade, 23.XI.2009, J.D. García 1304 (UFP); 19.XII.2007, fl., A. AlvesAraújo \& D. Araújo 723 (IPA, UFP); Mata de Vespas, 12.XI.2007, fl. e fr., P.Y. Ojima 103 (IPA, UFP).

Amplamente distribuída na América do Sul (O’Donell 1941; Austin 1998b). No Brasil, é frequente principalmente em áreas de Mata Atlântica. $\mathrm{Na}$ Usina São José, é comum e facilmente reconhecida pelas folhas palmadas e, quando em frutificação, pelas cápsulas com sépalas persistentes, acrescentes e com coloração dourada.

12. Merremia umbellata (L.) Hallier f., Bot. Jahrb. Syst. 16(4-5): 552. 1893.

Fig. $4 \mathrm{i}-\mathrm{j}$

Trepadeira herbácea, látex não observado. Ramos puberulentos. Folhas 3,7-8,8 × 1,8-6,2 cm, membranáceas, inteiras a discretamente sinuosas, ovadas, base profundamente cordada, ápice acuminado a mucrunado, face abaxial com tricomas restritos à região das nervuras secundárias, face adaxial glabrescente; venação actinódroma, 6 pares de nervuras secundárias. Pecíolo 1-4,5 cm compr., tomentuloso. Umbela 6-8-flora, pedicelos ca. 1,5 cm compr., glabros; pedúnculo 4,8-8,2 cm compr. Sépalas subiguais, $9-10 \times 6-8 \mathrm{~mm}$ compr., côncavas, largamente elípticas, base arredondada, ápice obtuso, glabras. Corola ca. $3 \mathrm{~cm}$ compr., infundibuliforme, tubo muito estreito na base, glabra, tricomas às vezes restritos ao ápice das plicas, amarela. Estames ca. $4 \mathrm{~mm}$ compr., insertos, com tricomas na base; disco nectarífero presente; ovário 2-locular, 2 óvulos por lóculo. Cápsula ca. $1,5 \mathrm{~cm}$ compr., globosa.

Material examinado: Mata de Piedade, 17.IX.2009, fl., J.D. García 1121 (UFP); Mata de Zambana, 19.X.2007, fl. e fr., A. Alves-Araújo et al. 665 (IPA, UFP). 


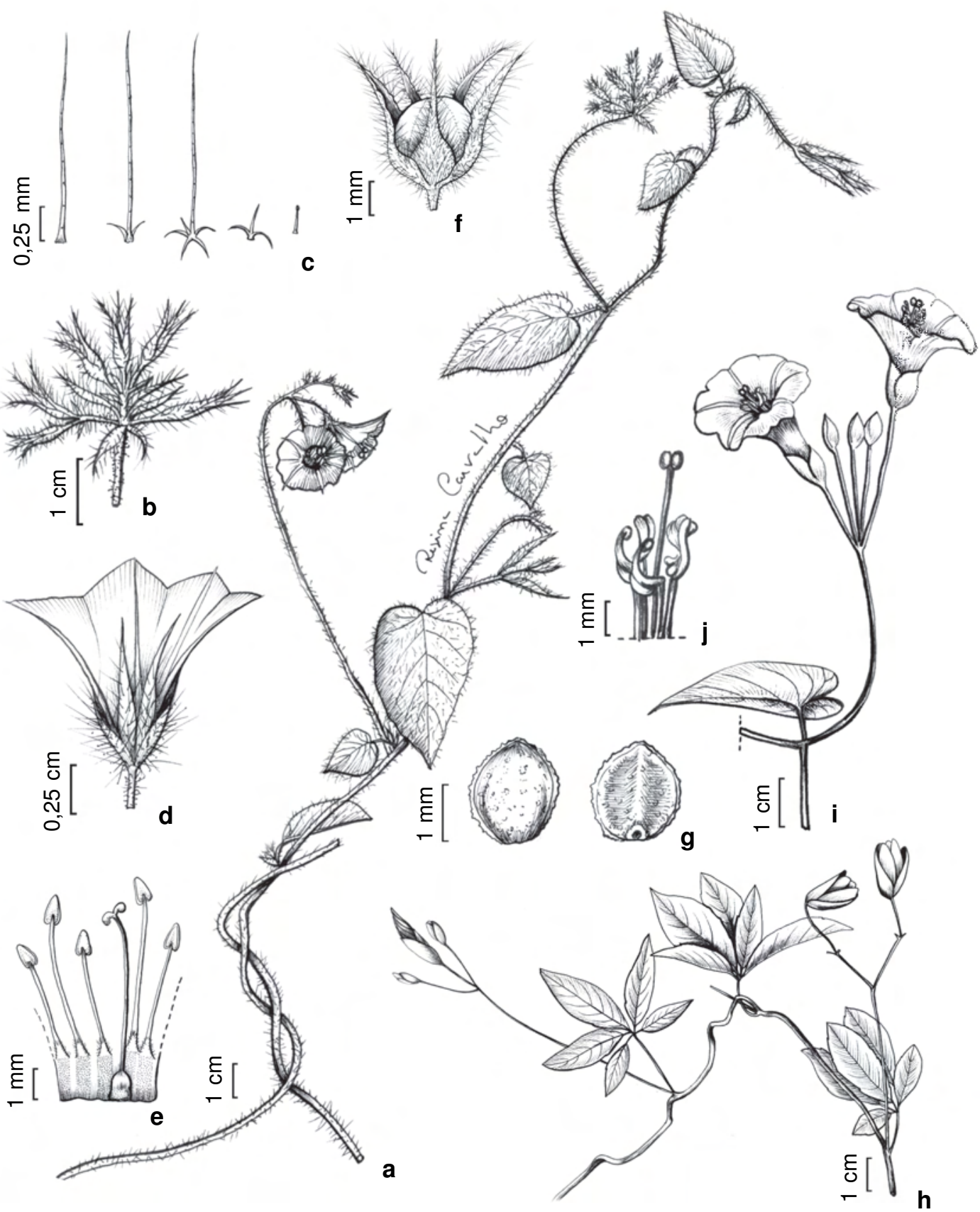

Figura 4 - a-g. Jacquemontia sphaerostigma (García 1117) - a. ramo florífero; b. inflorescência; c. tricomas, da esquerda para direita, simples, 3-ramificado com 1 braço bem mais longo, 6-ramificado com 1 braço bem mais longo, 3-ramificado com todos os braços iguais, glandular; d. flor; e. androceu e gineceu; f. fruto; g. semente, face dorsal à esquerda, face ventral à direta. h. Merremia macrocalyx (Ojima 103) - ramo florífero. i-j. M. umbellata (AlvesAraújo 665) - i. ramo florífero; j. detalhe das anteras e lobos estigmáticos.

Figure 4 - a-g. Jacquemontia sphaerostigma (García 1117) - a. fertile branch; b. inflorescence; c. trichomes, from left to right, simple, 3-branched with 1 arm longer, 6-branched with 1 arm longer, 3-brached with equal arms, glandular; d. flower; e. androecium and gynoecium; f. fruit; g. seed, dorsal face at left, ventral face at right. h. Merremia macrocalyx (Ojima 103) - fertile branch. $\mathrm{i}-\mathrm{j}$. M. umbellata (Alves-Araújo 665) - i. fertile branch; j. detail of anthers and stigmatic lobes. 
Pantropical (Austin 1998b), bastante cultivada como ornamental. Na Usina São José, ocorre principalmente nas bordas dos fragmentos, e pode ser facilmente reconhecida quando em estágio florífero, pela coloração amarela intensa da corola.

\section{Agradecimentos}

A primeira autora agradece à FACEPE, a bolsa de Doutorado concedida, aos curadores dos Herbários visitados, a presteza durante a consulta das coleções, à Regina Carvalho as ilustrações botânicas, e à Dra. Rosângela SimãoBianchini pelas valiosas discussões sobre Convolvulaceae. Este estudo foi apoiado pela FACEPE e pelo CNPq.

\section{Referências}

Alves-Araújo, A. \& Alves, M. 2010. Flora da Usina São José, Igarassu, Pernambuco: Sapotaceae. Rodriguésia 61: 303-318.

Alves-Araújo, A.; Araújo, D.; Marques, J.; Melo, A.; Maciel, J.R.; Uirapuã, J.; Pontes, T.; Lucena, M.F.A.; du Bocage, A.L. \& Alves, M. 2008. Diversity of angiosperms in fragments of Atlantic Forest in the state of Pernambuco, Northeastern Brazil. Bioremediation, Biodiverstity and Bioavailability 2: 14-26.

Austin, D.F. 1975. Family 164: Convolvulaceae. In: Woodson, R.E. \& Schery, R.W. (orgs.) Flora of Panama. Part IX. Annals of the Missouri Botanical Garden 62: 157-224.

Austin, D.F. 1998a. Convolvulaceae. Morning Glory family. Journal of the Arizona-Nevada Academy of Science 30: 61-83.

Austin, D.F. 1998b. Convolvulaceae. In: Steyermark, J.A.; Berry, P.E. \& Holst, B.K. (eds.). Flora of the Venezuelan Guayana, 4. Missouri Botanical Garden Press, Saint Louis. Pp. 377-424.

Austin, D.F. \& Cavalcante, P.B. 1982. Convolvuláceas da Amazônia. Museu Paraense Emilio Goeldi, Belém. 134p.

Austin, D.F. \& Huáman, Z. 1996. A synopsis of Ipomoea (Convolvulaceae) in the Americas. Taxon 45: 3-38.

Buril, M.T. 2009. Convolvulaceae. In: Alves, M.; Araújo, M.F.; Maciel, J.R. \& Martins, S. (es.). Flora de Mirandiba. Associação Plantas do Nordeste, Recife. Pp. 121-134.

Cervenka, F.; Koleckar, V.; Rehakova, Z.; Jahodar, L.; Kunes, J.; Opletal, L.; Hyspler, R.; Jun, D. \& Kuka, K. 2008. Evaluation of natural substances from Evolvulus alsinoides L. with the purpose of determining their antioxidant potency. Journal of Enzyme Inhibition and Medicial Chemistry 23: 574-578.
Durigon, J.; Canto-Dorow, T.S. \& Eisinger, S.M. 2009. Composição florística de trepadeiras ocorrentes em bordas de fragmentos de floresta estacional, Santa Maria, Rio Grande do Sul, Brasil. Rodriguésia 60: 415-422.

Gentry, A.H. 1991. The distribution and evolution of climbing plants. In: Putz, F.E. \& Mooney, H.A. (eds.). The biology of vines. Cambridge University Press, Cambridge. Pp. 3-49.

Gentry, A.H. 1996. A field guide to the families and genera of woody plants of Northwest South America. University of Chicago Press, Chicago. Pp. 445-454.

Gonçalves, E.G. \& Lorenzi, H. 2007. Morfologia vegetal: organografia e dicionário ilustrado de morfologia das plantas vasculares. Instituto Plantarum de Estudos da Flora, Nova Odessa. 416p.

Harris, J.G. \& Harris M.W. 2000. Plant identification terminology: an illustrated glossary. Spring Lake Publishing, Spring Lake. 197p.

Mabberley, D.J. 1987. The plant book. Cambridge University Press, Cambridge. 699p.

Mori, S.A.; Mattos-Silva, L.A.; Lisboa, G. \& Coradin, L. 1985. Manual de manejo do herbário fanerogâmico. Centro de Pesquisas do Cacau, Ilhéus. 97p.

O’Donell, C.A. 1941. Revisión de las especies americanas de Merremia. Lilloa 6: 467-554.

O’Donell, C.A. 1953. Convolvuláceas americanas nuevas o criticas IV. Lilloa 26: 353-400.

Padda, M.S. \& Picha, D.H. 2008. Phenolic composition and antioxidant capacity of different heat-processed forms of sweetpotato cv. 'Beauregard'. International Journal of Food Science and Technology 43: 1404-1409.

Ribeiro, J.E.L.S.; Hopkins, M.J.G.; Vicentini, A.; Sothers, C.A.; Costa, M.A.S.; Brito, J.M.; Souza, M.A.D.; Martins, L.H.P.; Lohmann, L.G.; Assunção, P.A.C.L.; Pereira, E.C.; Silva, C.F.; Mesquita, M.R. \& Procópio, L.C. 1999. Flora da Reserva Ducke: guia de identificação das plantas vasculares de uma floresta de terra-firme na Amazônia Central. Instituto Nacional de Pesquisas da Amazônia, Manaus. 798p.

Robertson, K.R. 1971. A revision of the genus Jacquemontia (Convolvulaceae) in North and Central America and the West Indies. Tese de Doutorado. Washington University, St. Louis. 273p.

Simão-Bianchini, R. 1998. Ipomoea no Sudeste do Brasil. Tese de Doutorado. Instituto de Botânica, São Paulo. 476p.

Simão-Bianchini, R. 2009. Convolvulaceae. In: Stehmann, J.R.; Forzza, R.C.; Salino, A.; Sobral, M.; Costa, D.P. \& Kamino, L.H.Y. 2009. Plantas da Floresta Atlântica. Jardim Botânico do Rio de Janeiro, Rio de Janeiro. 515p.

Simão-Bianchini, R. \& Pirani, J.R. 1997. Flora da Serra do Cipó, Minas Gerais: Convolvulaceae. Boletim de Botânica da Universidade de São Paulo 16: 125-149. 
Simão-Bianchini, R. \& Pirani, J.R. 2005. Duas novas espécies de Convolvulaceae de Minas Gerais, Brasil. Hoehnea 32: 295-300.

Smith, N.; Mori, A.; Henderson, A.; Stevenson, D.W. \& Heald, S.V. 2004. Flowering plants of the Neotropics. Princeton University Press, Princeton. Pp. 229-232.

Souza, V.C. \& Lorenzi, H. 2005. Botânica sistemática. Instituto Plantarum de Estudos da Flora, Nova Odessa. 640p.

Stearn, W.T. 2004. Botanical Latin. 4 ed. David \& Charles Publishers, Newton Abbot. 546p.

Thiers, B. 2009 [continuously updated]. Index Herbariorum: a global directory of public herbaria and associated staff. New York Botanical Garden's Virtual Herbarium. Disponível em <http://sweetgum. nybg.org/ih> Aacesso em 15 fevereiro 2010.

Tibiriçá, Y.J.A.; Coelho, L.F.M. \& Moura, L.C. 2006. Florística de lianas em um fragmento de floresta estacional semidecidual, Parque Estadual de Vassununga, Santa Rita do Passa Quatro, SP, Brasil. Acta Botanica Brasilica 20: 339-346.

Trindade, M.B.; Lins-e-Silva, A.C.B.; Silva, H.P.; Figueira, S.B. \& Schessl, M. 2008. Fragmentation of the Atlantic rainforest in the Northern coastal region in Pernambuco, Brazil: recent changes and implications for conservation. Bioremediation, Biodiversity and Bioavailability 2: 5-13.

Udulutsch, R.G.; Assis, M.A. \& Picchi, D.G. 2004. Florística de trepadeiras numa floresta estacional semidecídua, Rio Claro - Araras, estado de São Paulo, Brasil. Revista Brasileira de Botânica 27: 125-134

Yen, F.L.; Wu, T.H.; Lin, L.T.; Cham, T.M. \& Lin, C.C. 2008. Concordances between antioxidant activities and flavonol contents in different extracts and fractions of Cuscuta chinensis. Food Chemistry 108: 455-462.

\section{Lista de Exsicatas}

Alves-Araújo, A. 531 (8); 665 (12); 723 (11); Carvalho, A.M. 3511 (1); Cavalcanti, D. 25 (2); Chisppeta, A. 556 (1); García, J.D. 935 (7); 976 (1); 977 (9); 990 (9); 1088 (3); 1095 (9); 1099 (9); 1100 (6); 1104 (9); 1117 (10); 1121 (12); 1159 (3); 1161 (9); 1212 (4); 1216 (1); 1251 (6); 1304 (11); 1339 (1); Melo, M. 95 (9); 141 (4); 358 (7); Nascimento, L.M. 655 (5); Ojima, P.Y. 103 (11); 110 (3); 115 (3); Pinheiro, K. 114 (6); Sobrinho, M.S. 576 (2). 